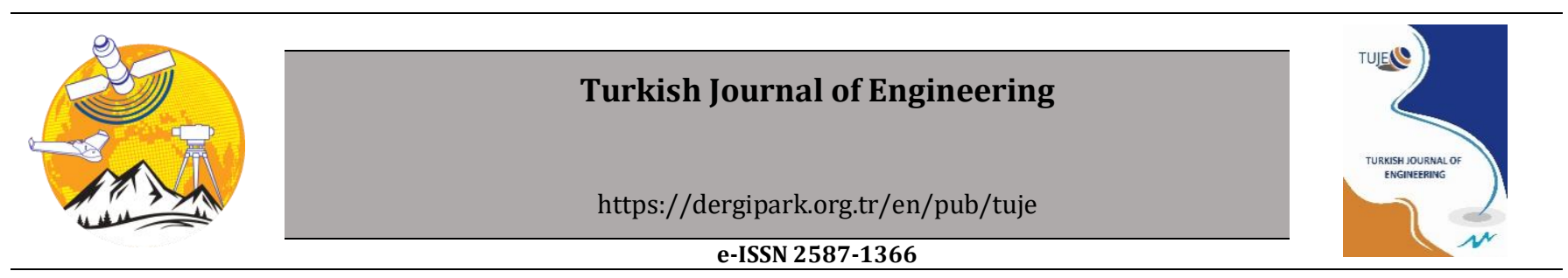

\title{
Microstructure and mechanical properties of similar and dissimilar laser welds of dp600 and dp1000 steel sheets used in the automotive industry
}

\author{
Oguz Tuncel $^{* 1}$, Hakan Aydın ${ }^{1}$, Sukriye Cetin $1{ }^{\circledR}$ \\ ${ }^{1}$ Bursa Uludağ University, Engineering Faculty, Mechanical Engineering Department, Bursa, Turkey
}

\author{
Keywords \\ $\mathrm{Nd}$ :YAG laser welding \\ DP600 steel \\ DP1000 steel \\ Mechanical properties \\ Microstructure
}

\begin{abstract}
Dual-phase (DP) steel sheets are the most widely used steel group in the automotive industry. When these steel sheets are used in car body components, welding is inevitably needed during the manufacturing process. Although the resistance spot welding (RSW) is the most widely used welding method in the automotive industry, the newly popular laser welding has gained more importance in the welding of these steel grades in recent years. In this work, the DP600 and DP1000 steel sheets were joined as double-sided with the pulsed Nd: YAG (Neodymiumdoped Yttrium Aluminum Garnet (Y3Al5012)) laser welding. Performing similar or dissimilar weld of DP steel sheets is an inevitable demand in the modern automotive industry. So, in this study similar (DP600-DP600, DP1000-DP1000) and dissimilar (DP600-DP1000) steel sheets were welded in the flat position with the butt joint. In order to evaluate welding performance, microstructural studies and mechanical tests were performed, and experiments carried out in this context include optical microscope studies, tensile tests and Vickers microhardness measurements. The tensile strength of the similar welded joints is a little bit lower than the base metals (BM). But, for dissimilar weld, the tensile strength is even lower than DP600DP600 joint. And the microstructure of the welded joints are composed of martensite, retained austenite and bainite in the fusion zone and a mixture of martensite, bainite, ferrite, retained austenite and tempered martensite in heat affected zone (HAZ).
\end{abstract}

\section{INTRODUCTION}

Dual-phase (DP) steels have commonly used as advanced high strength steel (AHSS) in the automotive industry nowadays to reduce vehicle weight, improve fuel economy and passenger safety. The term dual phase is due to its microstructure. The combination of DP steels consists of soft ferrite matrix and hard martensitic phase. In this combination of two phases, hard martensite phase provides the high strength and soft ferrite matrix provides good formability and ductility. The volume fraction of the martensite determines the strength and grade of the DP steel (Liu et al. 2015; Dong et al. 2014; Saha et al. 2014). The steels used automotive industry must be easy formable, weldable, coatable and repairable. For having these features, DP steels are being implemented in auto-body parts easily like floor panel, hood outer, quarter panel inner, rear rails, safety cage components, etc. (Bandyopadhyay et al. 2016; Hazratinezhad et al. 2012)

Welding is the mostly used joining technique during the manufacturing of automotive body components.
Recently, laser welding has gained popularity because of flexibility, ease of automation, high welding speed, high power density, small heat affected zone (HAZ), high weld bead depth-to-width ratio and low thermal distortion of the workpiece. So, laser welding has been considered potentially replace with other commonly used fusion welding techniques such as resistance and arc welding (Sharma and Molian 2011; Yuce et al. 2017; Mohammadpour et al. 2018 ). Also, pulsed Nd:YAG laser welding has several advantages over the other laser sources because of control the laser parameters precisely including pulse duration and pulse frequency (Hekmatjou and Naffakh-Moosavy 2018).

There are several studies on the laser welding of DP steels in the literature. (Parkes et al. 2013) studied the evaluation the microstructure and fatigue properties of fiber laser welded (FLWed) high strength low alloy (HSLA) and dual-phase (DP980) steels in similar and dissimilar combinations. The weld zone contained martensite, bainite, tempered martensite, and ferrite phases. Soft zone occurred on DP980 side and lower microhardness values than the base metal (BM) were 
measured in this zone. (Fernandes et al. 2017) aimed to determine the weldability and optimum welding parameters of Nd: YAG laser welded DP600 sheets. As a result of the hardness studies, they found a hardness increase of nearly $100 \%$ in the melting zone compared to the BM. (Wang et al. 2016) investigated the effect of energy input on the microstructure and mechanical properties of DP1000 steel butt joint using Nd:YAG laser welding. They measured $86-91 \%$ of the strength of the DP1000 steel BM of laser welded joints, and detected tempered martensite in the HAZ. (Xia et al. 2008) made the Nd:YAG laser welds on DP450, DP600 and DP980 steels over a wide range of heat inputs. In the result of their study, the total extent of HAZ softening in a DP weld at large heat input was proportional to the martensite content of the steel. (Węglowski et al. 2009) investigated the microstructure, mechanical properties, fatigue strength and residual stresses of laser welded dual phase HDT580X steel. The results of their study revealed that the HDT 580X steel was characterized by good laser weldability. In their study, the tensile strength of the welded joints was about BM, and microstructure of the welded joints was composed of lath martensite in the fusion zone and mixture of lath martensite, bainite and ferrite in the HAZ. (Sun et al. 2016) studied the metallurgical phenomena of welded joints of DP590 steel sheets using pulsed laser with increasing pulse frequency. They showed that increasing pulse led to an increase in overlapping factor (-22.5\%-75.5\%) and average power between two laser spots, which could result in penetration depth increasing. Also, in their study over $54.5 \%$ overlapping factor, they achieved $100 \%$ penetration depth. (Di et al. 2017) fiber laser welded $1.5 \mathrm{~mm}$ thick dissimilar DP780 and DP980 steel sheets. In their study, in the HAZ region tempered martensite and retained austenite were the reason of the decrease in hardness compared the BM.

This study aims to investigate the pulsed Nd:YAG laser welding capabilities of similar and dissimilar DP steels (DP600-DP600, DP600-DP1000, DP1000DP1000), which are increasingly used in the automobile industry. Welding operations were conducted as doublesided. Vickers microhardness measurements and tensile tests were carried out to determine the mechanical properties of welds. Also, the weld region was examined using an optical microscope for macrostructure and microstructure studies.

\section{EXPERIMENTAL DETAILS}

Commercial DP600 and DP1000 steel sheets with a thickness of $1 \mathrm{~mm}$ were selected for this study. The chemical composition and tensile properties of the BM's were listed in Tab. 1 and 2, respectively. DP600 and DP1000 steel sheets were cut into pieces in dimensions of $100 \mathrm{~mm}$ x $260 \mathrm{~mm}$ before the welding processes. Laser welding operations were performed by assembling the sheets in the square butt-joint configuration using a pulsed SISMA SWA $300 \mathrm{Nd}$ :YAG laser welding machine with a maximum mean power of $300 \mathrm{~W}$. A special fixture was made to ensure complete contact between the forehead surface of the weld samples, and this fixture was mounted to the workbench of the welding machine
(Fig. 1). All welds were conducted perpendicular to the rolling direction (Fig. 2a). Argon shielding gas was employed during laser welding operations. The focal length was $120 \mathrm{~mm}$ above the sheet surface. The capacity of the welding device was insufficient for single-sided welding. Therefore the welds were performed as doublesided DP600-DP600, DP600-DP1000 and DP1000DP1000 in constant parameters $65 \%$ charge, 5 ms pulse duration, $5 \mathrm{~Hz}$ frequency, $1.4 \mathrm{~mm}$ focal spot diameter and $4 \mathrm{~mm} / \mathrm{s}$ welding speed (Table 3 ). In the double-sided welding process, first the front face was welded, then the other face was welded. Weld parameters were chosen according to the experience of the authors in their previous studies and the welding device capacity also considered. With these parameters overlapping factor calculated $43.66 \%$ by using the formula in Eq. 1 (Sun et al. 2016).

$$
\mathrm{Q}_{\mathrm{f}}=[1-(\mathrm{V} / \mathrm{f}) /(\mathrm{D}+\mathrm{VT})] \times 100
$$

Where $\mathrm{V}$ is welding speed $(4 \mathrm{~mm} / \mathrm{s}), \mathrm{f}$ is pulse frequency $(5 \mathrm{hz}), \mathrm{T}$ is pulse duration $(5 \mathrm{~ms})$ and $\mathrm{D}$ refers to laser spot size on the workpiece $(1.4 \mathrm{~mm})$.

The welded samples were machined perpendicular to the welding direction in accordance with ASTM E8/E8M (ASTM 2009) (Fig. 2b). To evaluate the mechanical properties of the welds, the uniaxial tensile tests were carried out on a computerized UTEST-7014 tensile testing machine at room temperature with a constant crosshead displacement speed of $5 \mathrm{~mm} / \mathrm{min}$. The tensile properties were evaluated by averaging the value of five specimens under the same welding condition. An extensometer with a gauge length of $65 \mathrm{~mm}$ was used to measure the elongation during the tensile tests. After welding, optical microscopy was used to characterize the macrostructure and microstructure of the welded samples. Before the microstructure and microhardness studies metallographic specimens were cut from the weld cross-section, grounding and polishing processes were carried out, and then samples etched with 3\% nital solution for 10-15 seconds. Vickers microhardness measurements were performed on the metallographic samples using a DUROLINE-M microhardness tester with a 100 gram load with a holding time of 10 seconds. Microhardness measurements were done from the first welding pass to see the effect of the final thermal cycle. The hardness values were measured spacing of $100 \mu \mathrm{m}$ along the center of the first pass.

Table 1. Chemical properties of DP600 and DP1000 steels

\begin{tabular}{llllll}
\hline Steel & $\mathrm{C}$ & $\mathrm{Mn}$ & $\mathrm{Si}$ & $\mathrm{Cu}+\mathrm{Cr}+\mathrm{Ni}$ & $\mathrm{Cr}$ \\
\hline DP600 & 0.12 & 1.40 & 0.5 & 1.3 & - \\
DP1000 & 0.16 & 1.89 & 0.26 & - & 0.44 \\
\hline
\end{tabular}

Table 2. Mechanical properties of DP600 and DP1000 steels

\begin{tabular}{cccc}
\hline Steel & $\begin{array}{l}\text { Yield } \\
\text { Strength (MPa) }\end{array}$ & $\begin{array}{l}\text { Tensile } \\
\text { Strength (MPa) }\end{array}$ & $\begin{array}{c}\text { Elongation } \\
(\%)\end{array}$ \\
\hline DP600 & 370 & 630 & 24 \\
DP1000 & 660 & 1020 & 13.5 \\
\hline
\end{tabular}




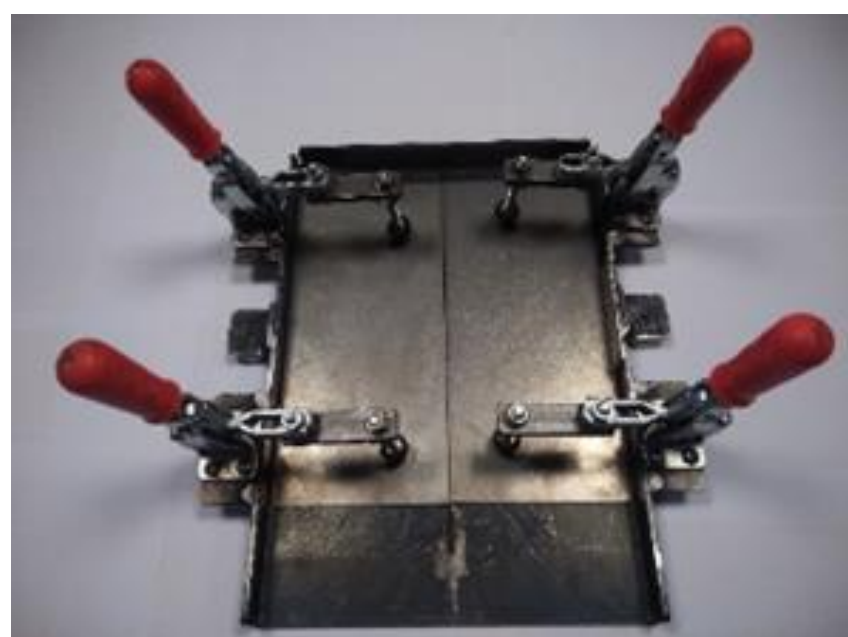

Figure 1. The fixture used in the welding operations

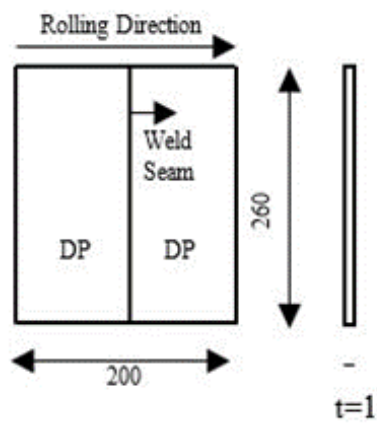

a)

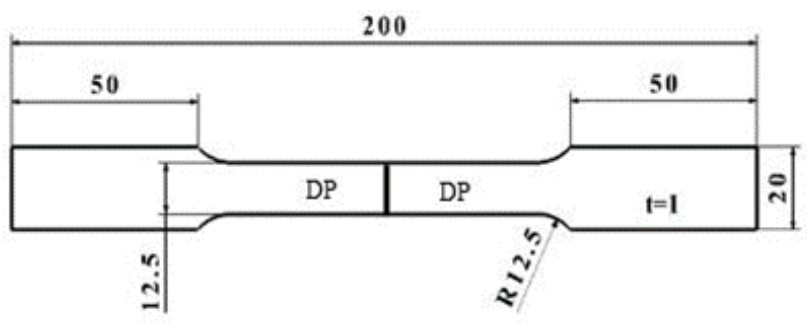

b)

Figure 2. a) Schematic illustration of laser welded DP steel sheets; b) Dimensions of the tensile test specimens

Table 3. Welding parameters used in this study

\begin{tabular}{lllll}
\hline Charge & $\begin{array}{l}\text { Pulse } \\
\text { Duration } \\
\text { Time }\end{array}$ & $\begin{array}{l}\text { Pulse } \\
\text { Frequency }\end{array}$ & $\begin{array}{l}\text { Focal } \\
\text { Spot } \\
\text { Diameter }\end{array}$ & $\begin{array}{l}\text { Welding } \\
\text { Speed }\end{array}$ \\
\hline$\%$ & $\mathrm{~ms}$ & $\mathrm{~Hz}$ & $\mathrm{~mm}$ & $\mathrm{~mm} / \mathrm{s}$ \\
\hline 65 & 5 & 5 & 1.4 & 4 \\
\hline
\end{tabular}

\section{RESULTS and DISCUSSIONS}

To determine the quality of the double-sided laser welded joints, the tensile strength of the joints were experimentally conducted using tensile tests. The tensile test results exhibited that the weld combination significantly affected the tensile performance of doublesided laser welded DP600-DP600, DP600-DP1000 and DP1000-DP1000 steel sheet joints at the same welding parameters (Tab. 4).

The tensile strength of Nd:YAG laser welded DP600DP600, DP600-DP1000 and DP1000-DP1000 steel sheets are shown in Fig. 3. The highest weld strength in these joints (880 MPa) was observed in DP1000-DP1000 joint. The lowest weld strength $(586.5 \mathrm{MPa})$ was found in DP600-DP1000 joints. On the other hand, the effect of welding combination on the elongation of the doublesided laser welded joints can also be seen in Fig. 4. The highest elongation in these joints $(29.12 \%)$ was for DP600-DP600 joint. And, the lowest elongation (8.82\%) was for DP1000-DP1000 joint. These elongation values are quite enough for the automobile industry.

Table 4. Tensile strength and elongation of the laser welded joints (average values)

\begin{tabular}{lll}
\hline Weld Combination & $\begin{array}{l}\text { Tensile } \\
\text { Strength (MPa) }\end{array}$ & Elongation (\%) \\
\hline DP600-DP600 & 610.6 & 29.12 \\
DP600-DP1000 & 586.5 & 15.46 \\
DP1000-DP1000 & 880 & 8.82 \\
\hline
\end{tabular}

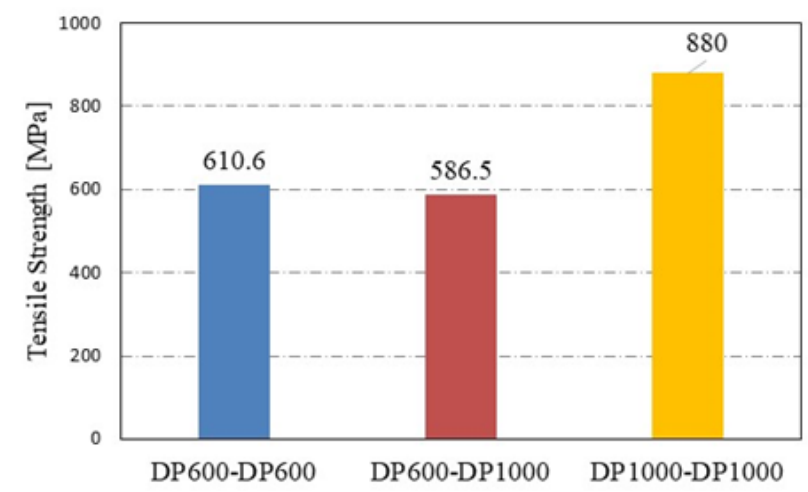

Figure 3. Tensile strength of Nd:YAG laser welded DP600-DP600, DP600-DP1000 and DP1000-DP1000 steel sheets

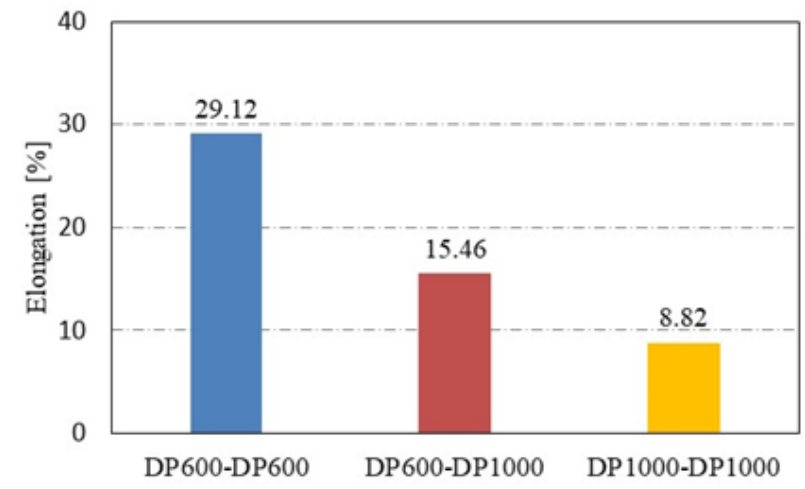

Figure 4. Elongation of Nd:YAG laser welded DP600DP600, DP600-DP1000 and DP1000-DP1000 steel sheets

Fig. 5, Fig. 6 and Fig. 7 show the microhardness measurement results of the samples produced with DP600-DP600, DP600-DP1000 and DP1000-DP1000 joints, respectively. Measurements were done at $100 \mu \mathrm{m}$ intervals along a line, starting from the center of the fusion zone until reaching the BM for similar welds. Also, dissimilar weld microhardness measurements were done from DP600 BM to DP1000 BM along a line with $100 \mu \mathrm{m}$ intervals. Different hardness values were measured in the fusion zone, HAZ and BM regions along the line. The highest hardness values were obtained in the fusion zone at three different welding combination (Fig. 5, Fig. 6 and Fig. 7). The effective martensite 
formation in the fusion zone is the reason why the highest hardness value obtained in this region. The increase in hardness as it moves away from the weld center in the fusion zones is due to the fine martensitic structures obtained as a result of relatively faster cooling. In three different samples, similarly narrow $\mathrm{HAZ}$ regions were observed. The width of the HAZ regions is roughly $300 \mu \mathrm{m}$. The hardness of these regions falls down from the fusion zone to the BM. This hardness drop is associated with a small amount of ferrite and tempered martensite near the BM. Furthermore, the tempering of the BM in a narrow area between the $\mathrm{HAZ}$ and the BM on the DP1000 sides caused significantly softening with the formation of ferrite and iron carbide (Fig.6, Fig.7).

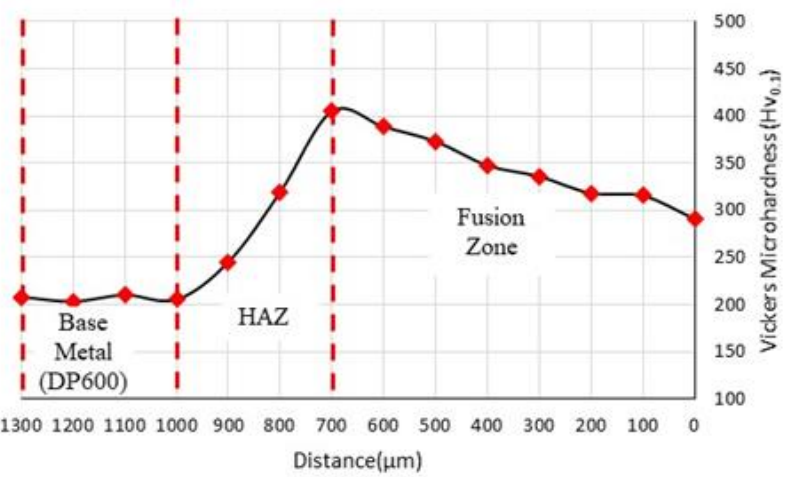

Figure 5. Microhardness variation of the weld zone in the DP600-DP600 sample

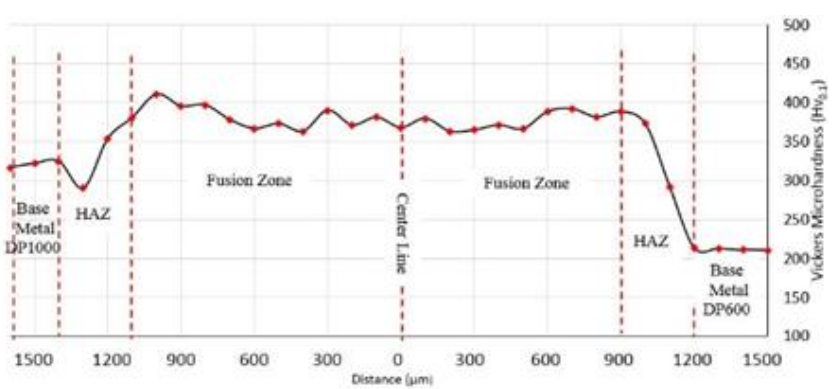

Figure 6. Microhardness variation of the weld zone in the DP600-DP1000 sample

Macro images of similar and dissimilar welded samples were shown in Fig 8. In Fig. 8a,b,c there were small black holes in the centre of weld zone because of insufficient weld penetration depth. Various regions from the weld zone were selected for microstructure examinations. And, $\mathrm{X}$ shape joint image was seen in all double-sided welded samples.

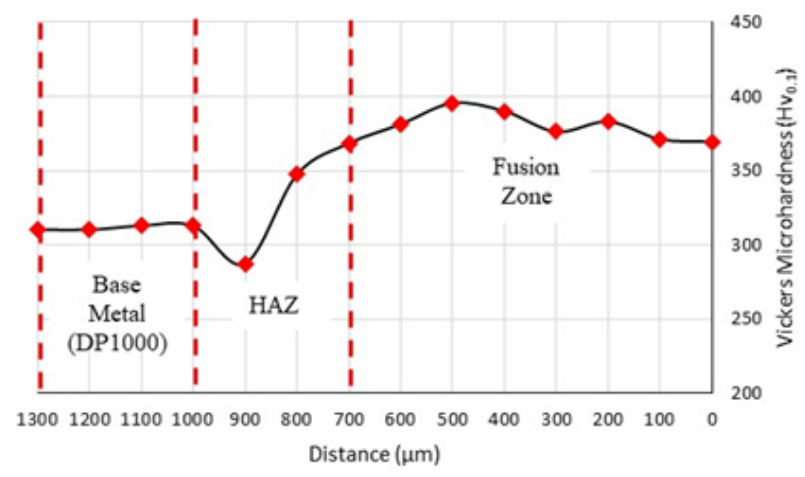

Figure 7. Microhardness variation of the weld zone in the DP1000-DP1000 sample

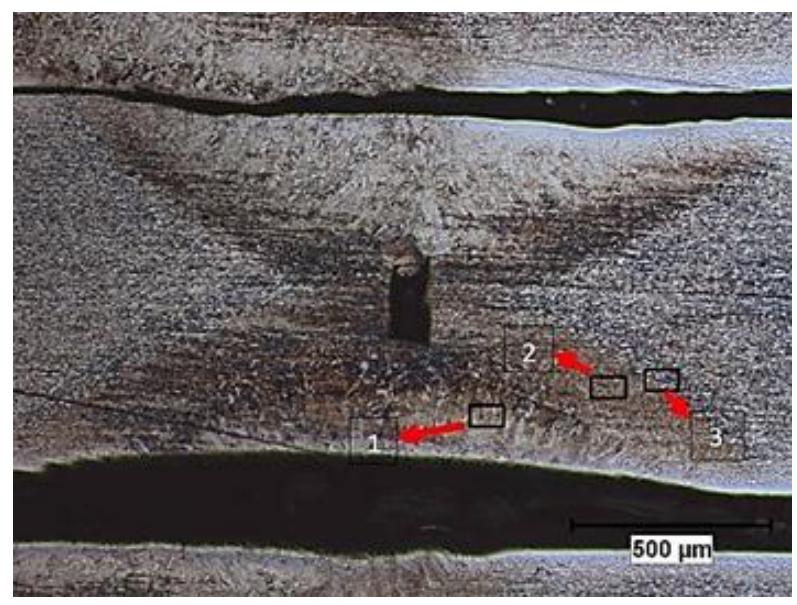

(a)

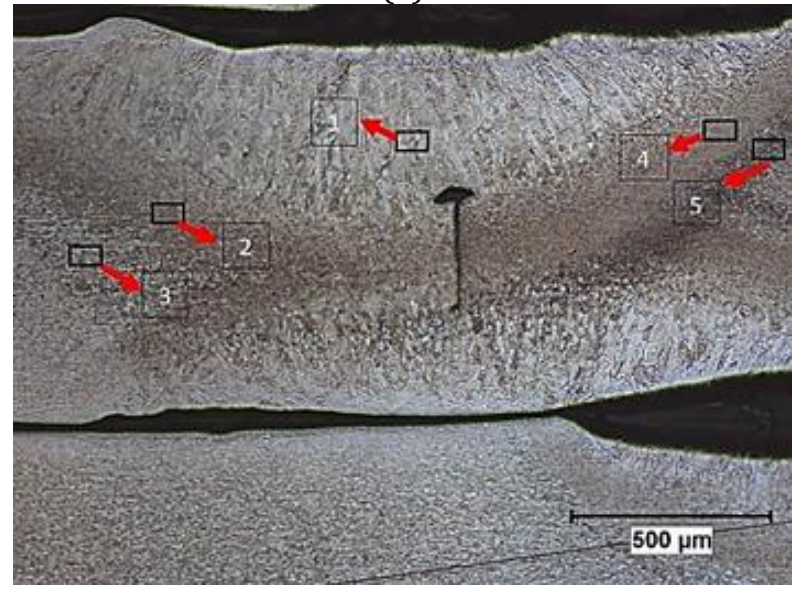

(b)

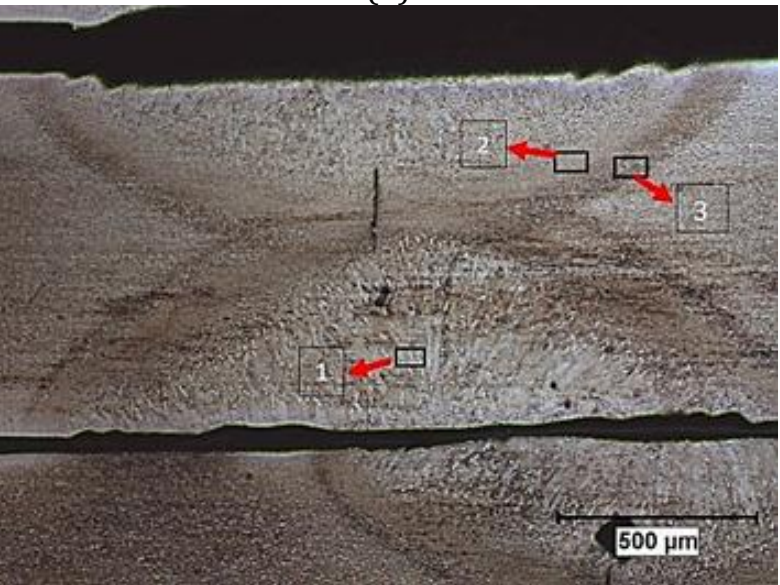

(c)

Figure 8. Macro images of the welded samples a) DP600DP600, b) DP600-DP1000, c) DP1000-DP1000

Images of marked regions for DP600-DP600 joint in Fig. 8a were showed in Fig. 9. In Fig. 8 1st, 2nd and 3rd regions show fusion zone, HAZ and intersection of HAZ and $\mathrm{BM}$, respectively. In the 1st region, melting was achieved as a result of heat input and then as a result of rapid cooling which is characteristic of laser welding, martensite and some bainite occurred (Fig 9a). The 2nd region contains the phases of bainite and tempered martensite, and some martensite near fusion zone (Fig 9b). And, the 3rd region has predominantly BM microstructure properties and there is a small amount of bainite and tempered martensite near HAZ in this region (Fig 9c). 


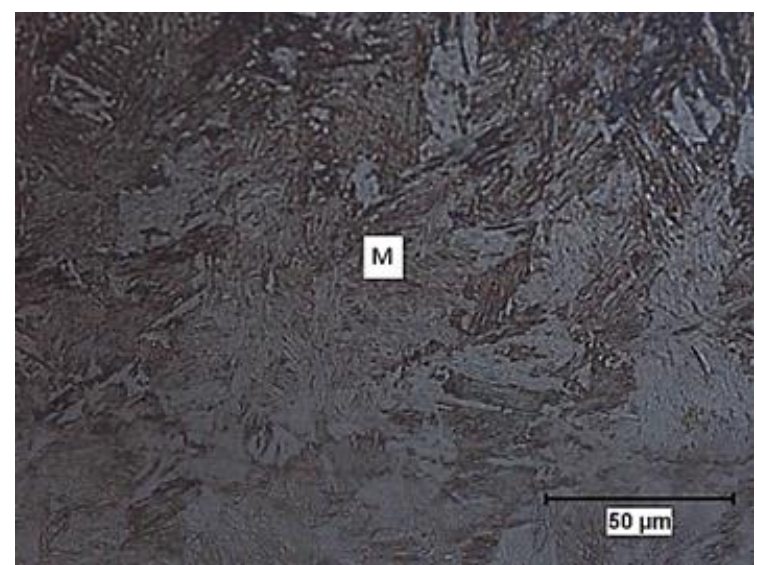

(a)

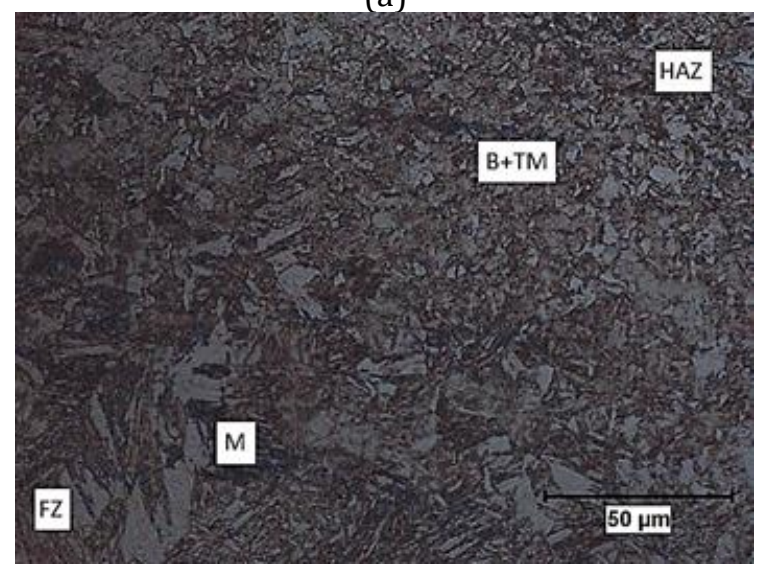

(b)

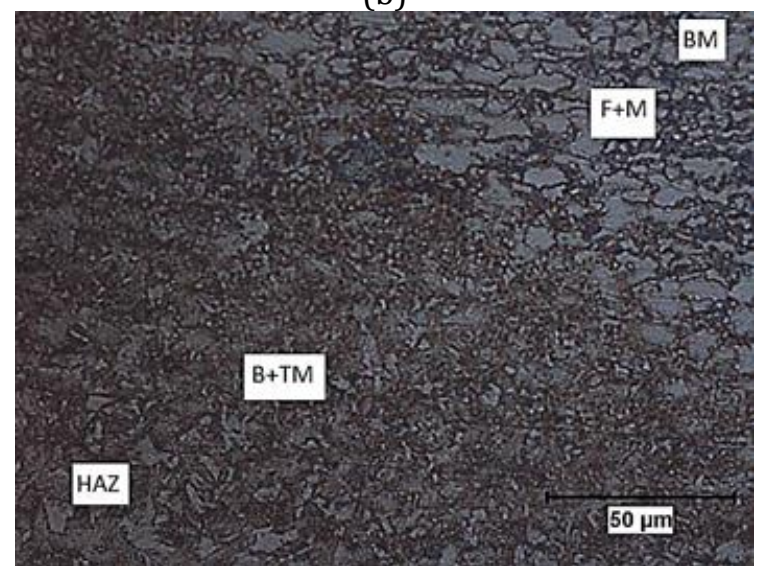

(c)

Figure 9. The microstructures of $\mathrm{Nd}$ :YAG laser welded DP600-DP600 joints a) Fusion zone b) HAZ c) Transition from HAZ to BM (F:Ferrite, M:Martensite, B:Bainite, TM: Tempered Martensite).

Images of marked regions for DP600-DP1000 joint in Fig. 8b were showed in Fig. 10. In Fig. $81^{\text {st }}, 2^{\text {nd }}, 3^{\text {rd }}, 4^{\text {th }}$ and $5^{\text {th }}$ regions show fusion zone, HAZ on DP600 side, the intersection of HAZ and BM on DP600 side, HAZ on DP1000 side and the intersection of HAZ and BM on DP1000 side, respectively. The $1^{\text {st }}$ region consists entirely of lath martensite (Fig. $10 \mathrm{a}$ ). The $2^{\text {nd }}$ region is composed of bainite and tempered martensite (Fig 10b). The $3^{\text {rd }}$ region has highly BM microstructural properties. Also, near HAZ on DP600 side, the tempered martensite and bainite are observed (Fig. 10c). The $4^{\text {th }}$ region consists of tempered martensite, retained austenite and bainite mixture (Fig 10d). The $5^{\text {th }}$ region, which is softened zone, contains tempered martensite, bainite, ferrite and iron carbides (Fig 10e).

Images of marked regions for DP1000-DP1000 joint in Fig. 8c were showed in Fig. 11. In Fig. $111^{\text {st }}$ region shows the fusion zone, $2^{\text {nd }}$ region $\mathrm{HAZ}$ and $3^{\text {rd }}$ region intersection of $\mathrm{HAZ}$ and $\mathrm{BM}$. In the $1^{\text {st }}$ region, martensite was formed completely and its thought there can be a little amount of retained austenite (Fig. 11a). The $2^{\text {nd }}$ region is in the HAZ, which consists of martensite, bainite, retained austenite and tempered martensite (Fig $11 \mathrm{a})$. The $3^{\text {rd }}$ region is in the intersection of HAZ and BM, which consists of tempered martensite, bainite and highly include BM phases (Ferrite+Martensite) (Fig 11c).

\section{CONCLUSION}

In this study, the effects of weld combination on microstructure and mechanical properties of DP600DP600, DP600-DP1000 and DP1000-DP1000 steel sheets welded with $\mathrm{Nd}$ : YAG laser device were investigated. The results obtained in this study are summarized as follows:

- In similar welds, DP600-DP600 weld strength approximately equal to BM strength $(97 \%$ of BM), but DP1000-DP1000 weld strength lower than the DP1000 BM strength ( $86 \%$ of BM). The reason for lower tensile strength of DP1000DP1000 weld is a big amount of hard martensite formation.

- In dissimilar weld (DP600-DP1000) tensile strength approximately equal to DP600 BM strength (93\% of DP600 BM).

- The hardness values obtained in the fusion zone are in complete harmony with the fusion zone microstructures. Hard lath martensitic phases have emerged in the fusion zones. This is the reason why the hardness values of the fusion zone are considerably higher than the BM.

- In the DP 1000 steel, a tempered BM structure (tempered martensite and ferrite) occurs between HAZ and the BM. As a result, lower hardness values than the BM were measured.

\section{ACKNOWLEDMENT}

This study is supported by the Scientific Research Fund (BAP) of Uludag University (Project Contract No. HDP (MH)-2017/47).

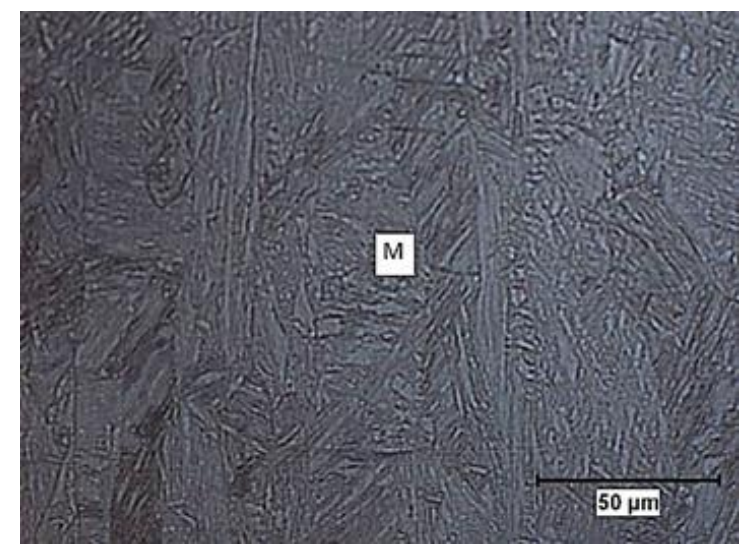

(a) 


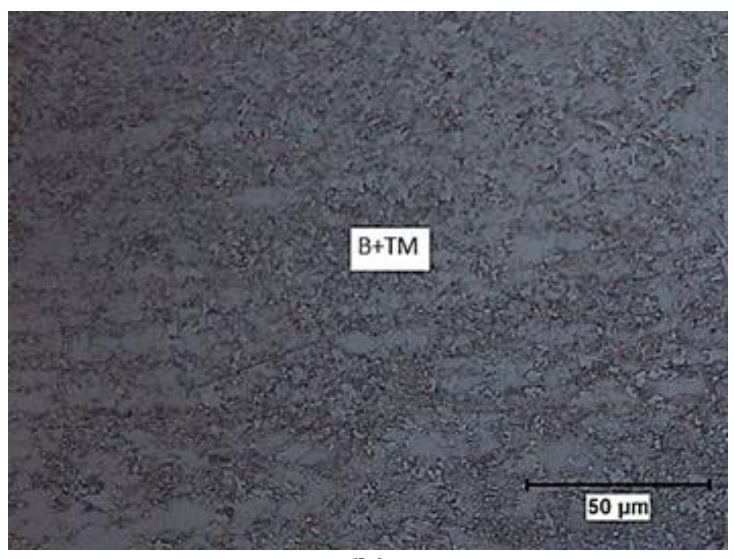

(b)

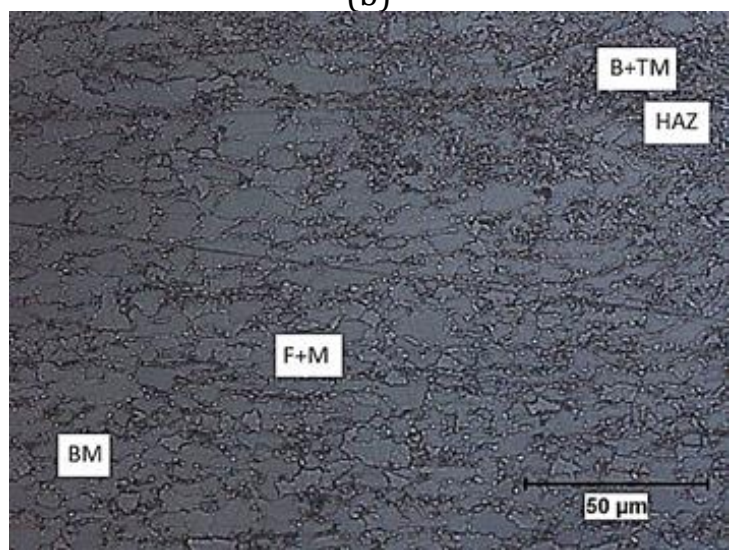

(c)

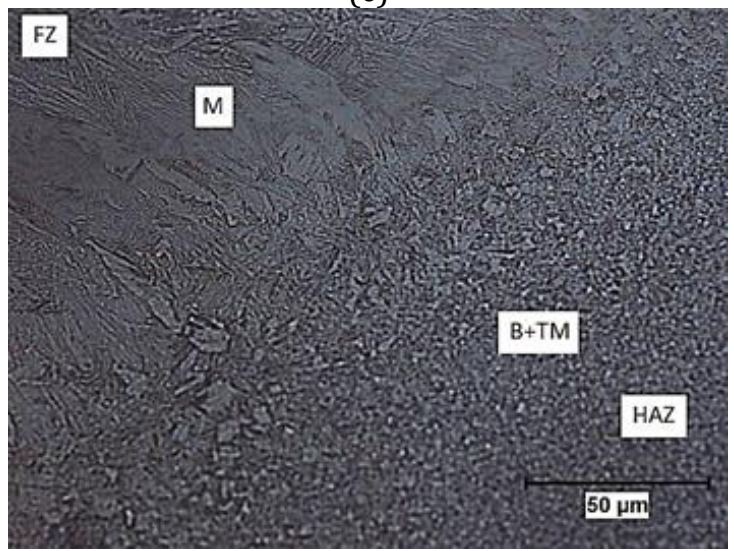

(d)

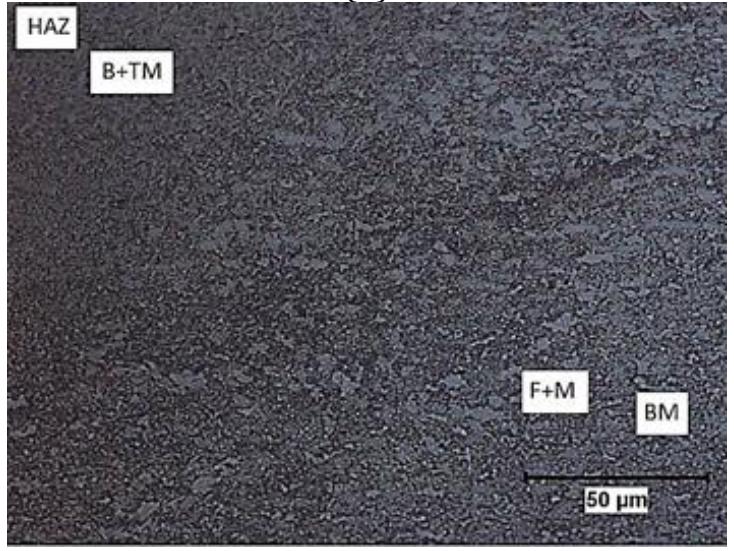

(e)

Figure 10. The microstructures of Nd:YAG laser welded DP600-DP1000 joints a) Fusion Zone b) HAZ on DP600 side c) Transition from HAZ to BM on DP600 side d) HAZ on DP1000 side e) Transition from HAZ to BM on DP1000 side (F:Ferrite, M:Martensite, B:Bainite, TM:Tempered Martensite).

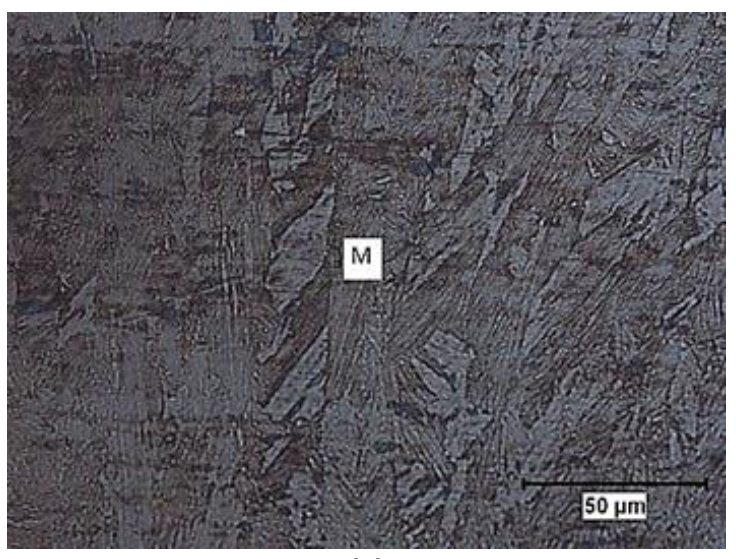

(a)

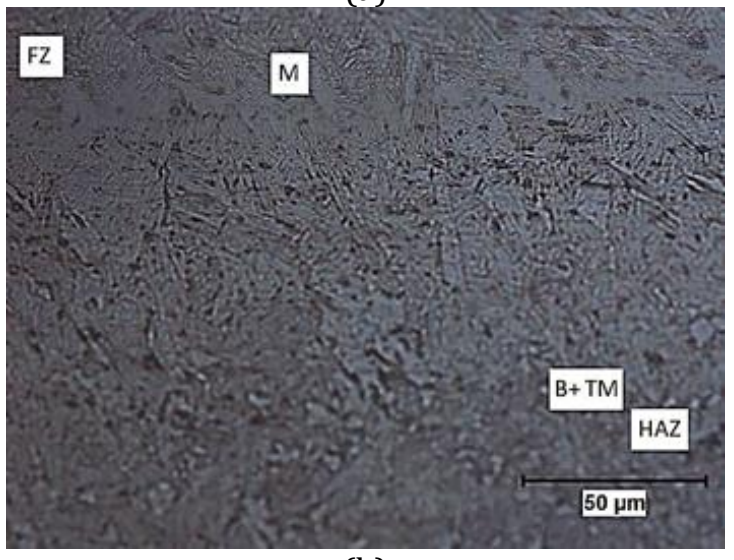

(b)

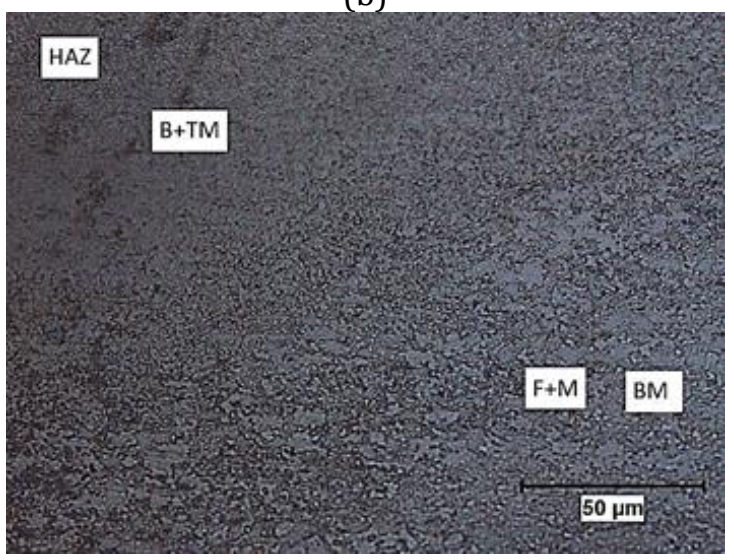

(c)

Figure 11. The microstructures of Nd:YAG laser welded DP1000-DP1000 joints a) Fusion zone b) HAZ c) Transition from HAZ to BM (F:Ferrite, M:Martensite, B: Bainite, TM: Tempered Martensite).

\section{REFERENCES}

ASTM E8/E8M. (2009). Standard Test Methods for Tension Testing of Metallic Materials.

Bandyopadhyay K, Panda S K, Saha P, BaltazarHernandez V H \& Zhou Y N (2016). Microstructures and failure analyses of DP980 laser welded blanks in formability context. Materials Science and Engineering: A, 652, 250-263. DOI: 10.1016/j.msea.2015.11.091

Di H, Sun Q, Wang X \& Li J (2017) Microstructure and properties in dissimilar/similar weld joints between DP780 and DP980 steels processed by fiber laser welding. Journal of Materials Science \& Technology, 
33(12),

1561-1571.

DOI:

10.1016/j.jmst.2017.09.001

Dong D, Liu Y, Yang Y, Li J, Ma M \& Jiang T (2014) Microstructure and dynamic tensile behavior of DP600 dual phase steel joint by laser welding. Materials Science \& Engineering: A, 594, 17-25. DOI: 10.1016/j.msea.2013.11.047

Fernandes F A O, Oliveira D F \& Pereira A B (2017). Optimal parameters for laser welding of advanced high-strength steels used in the automotive industry. Procedia Manufacturing, 13, 219-226. DOI: $10.1016 /$ j.promfg.2017.09.052

Hazratinezhad M, Mostafa Arab N B, Sufizadeh A R \& Torkamany M J (2012) Mechanical and metallurgical properties of pulsed neodymium-doped yttrium aluminum garnet laser welding of dual phase steels. Materials and Design, 33, 83-87. DOI: 10.1016/j.matdes.2011.06.070

Hekmatjou H \& Naffakh-Moosavy H (2018). Hot cracking in pulsed Nd:YAG laser welding of AA5456. Optics and Laser Technology, 103, 22-32. DOI: 10.1016/j.optlastec.2018.01.020

Liu Y, Dong D, Wang L, Chu X, Wang P \& Jin M (2015). Strain rate dependent deformation and failure behavior of laser welded DP780 steel joint under dynamic tensile loading. Materials Science and Engineering: A, 627, 296-305. DOI: 10.1016/j.msea.2014.12.103

Mohammadpour M, Yazdian N, Yang G, Wang H P, Carlson B \& Kovacevic, R (2018). Effect of dual laser beam on dissimilar welding-brazing of aluminum to galvanized steel. Optics and Laser Technology, 98, 214-228. DOI: 10.1016/j.optlastec.2017.07.035

Parkes D, Xu W, Westerbaan D, Nayak S S, Zhou Y, Goodwin F, Bhole S \& Chen D L (2013). Microstructure and fatigue properties of fiber laser welded dissimilar joints between high strength low alloy and dual-phase steels. Materials and Design, 51, 665-675. DOI: 10.1016/j.matdes.2013.04.076
Saha D C, Westerbaan D, Nayak S S, Biro E, Gerlich A P \& Zhou Y (2014) Microstructure-properties correlation in fiber laser welding of dual-phase and HSLA steels. Materials Science and Engineering: A, 607, 445-453. DOI: 10.1016/j.msea.2014.04.034

Sharma R S \& Molian P (2011) Weldability of advanced high strength steels using an Yb: YAG disk laser. Journal of Materials Processing Technology, 211(11), 1888-1897. DOI: 10.1016/j.jmatprotec.2011.06.009

Sun Q, Di H S, Li J C \& Wang X N (2016). Effect of pulse frequency on microstructure and properties of welded joints for dual phase steel by pulsed laser welding. Materials and Design, 105, 201-211. DOI: 10.1016/j.matdes.2016.05.071

Wang J, Yang L, Sun M, Liu T \& Li H (2016) Effect of energy input on the microstructure and properties of butt joints in DP1000 steel laser welding. Materials and Design, 90, 642-649. DOI: 10.1016/j.matdes.2015.11.006

Węglowski M S, Kwieciński K, Krasnowski K \& Jachym R (2009). Characteristics of Nd:YAG Laser Welded Joints of Dual Phase Steel. Archives of Civil and Mechanical Engineering, 9(4), 85-97. DOI: 10.1016/S1644-9665(12)60072-7

Xia M, Biro E, Tian Z L \& Zhou Y N (2008) Effects of heat input and martensite on HAZ softening in laser welding of dual phase steels. ISIJ International, 48(6), 809-814. DOI: 10.2355/isijinternational.48.809

Yuce C, Tutar M, Karpat F, Yavuz N \& Tekin G (2017). The effect of process parameters on the microstructure and mechanical performance of fiber laser-welded AA5182 aluminium alloys. Strojniski Vestnik/Journal of Mechanical Engineering, 63, 510-518.

(C) Author(s) 2021.

This work is distributed under https://creativecommons.org/licenses/by-sa/4.0/ 